\title{
Pleomorphic adenoma of the upper lip: A case report
}

\author{
A. Shrestha', N.S. Reddy², S. N. Ganguly ${ }^{3}$ \\ ${ }^{1}$ Lecturer, ${ }^{2}$ Prof. \& Head, ${ }^{3}$ Professor Department of ENT, College of Medical Sciences, Bharatpur, Chitwan, Nepal
}

\begin{abstract}
:
This case report describes a rare and unusual lesion found in 27 year old female, which was diagnosed as pleomorphic adenoma of the minor salivary glands in the upper lip. The tumor was a circumscribed, large firm mass, about $5 \mathrm{~cm}$ in diameter, almost obstructing the nasal vestibule and characterized by slow growth. Complete excision was performed and the histopathological analysis showed pleomorphic adenoma. The tumor did not recur. A brief review of the relevant literature is also presented.
\end{abstract}

Keywords: Pleomorphic adenoma; minor salivary gland tumors, nasal vestibule.

\section{Introduction}

The most common salivary gland tumor is Pleomorphic adenoma (PA), which accounts for 60$65 \%$ of such diseases. It mainly affects women in their fourth to sixth decade of life, and has a natural history of asymptomatic slow growth over a long period. ${ }^{1}$ It usually involves major salivary glands, most commonly being the tail of parotid. It also involves minor salivary glands. The lips are commonly affected sites, second only to the palate, and accounting for about $20-40 \%$ of all intraoral Pleomorphic adenoma. ${ }^{2,3}$

The aetiology of PA is unknown. It is epithelial in origin, and clonal chromosome abnormalities with aberrations involving $8 \mathrm{q} 12$ and $12 \mathrm{q} 15$ have been described. ${ }^{4}$

This paper describes the diagnosis and management of an asymptomatic, slowly growing, pleomorphic adenoma in the upper lip of middle aged female. Abrief review of the relevant literatures is also presented

Correspondence: Dr. A. Shrestha

Email:dr_amar2003@yahoo.com

\section{Case report}

A 27-year old female presented in ENT O.P.D. of this hospital with a complaint of painless, mobile lump in upper lip. The mass slowly increased in size during the past 3 years. At the time of presentation, nasal vestibule was almost obstructed by the mass as shown in fig-1. On examination, the mass was circumscribed, mobile, sessile, and rubbery in consistency and $4.5-5 \mathrm{~cm}$ in diameter as shown in fig2 . The overlying mucosa was smooth with pinkishpurple color showing evidence of superficial vascularity. Skin over the tumor was not fixed. There was no pain or bleeding on palpation. Head and neck abnormalities were not noted on clinical examination. The medical history was unremarkable, and no other abnormalities were found on clinical examination. Thus, the clinical diagnosis was benign minor salivary gland tumor. FNAC showed the features of pleomorphic adenoma. 


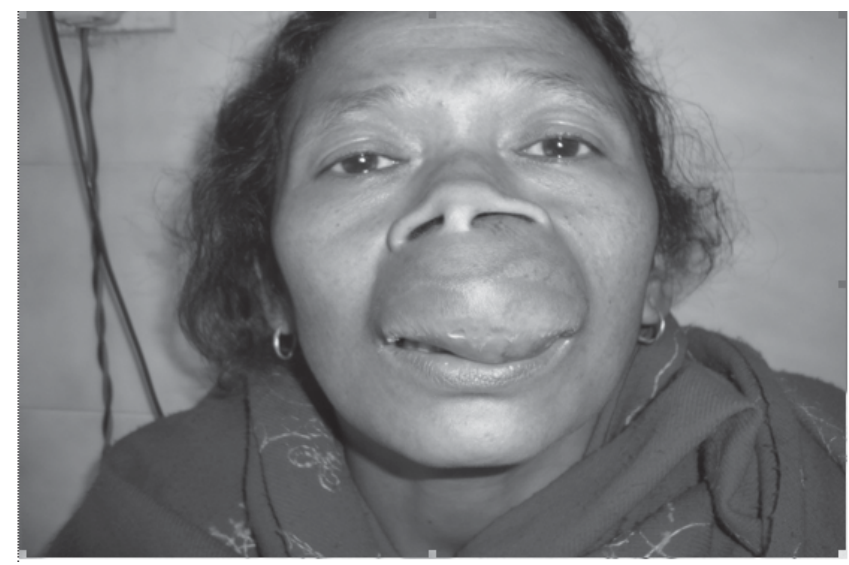

Fig- 1

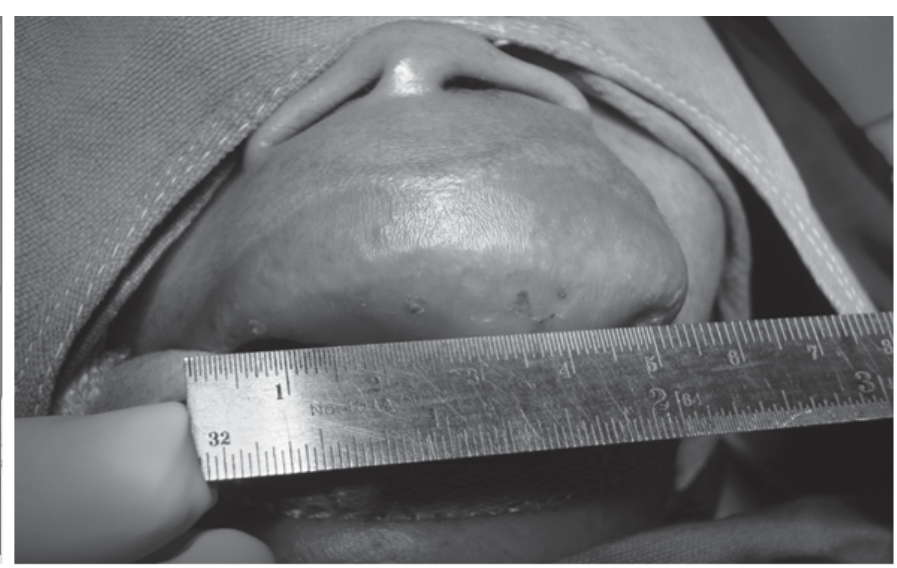

Fig-2

The tumor was completely removed with lip splitting incision as shown in fig-3. During the surgical procedure, the lesion was excised without difficulty with clinically normal margin because the mass was fully encapsulated. Subsequent follow up after one year showed no signs of recurrence.

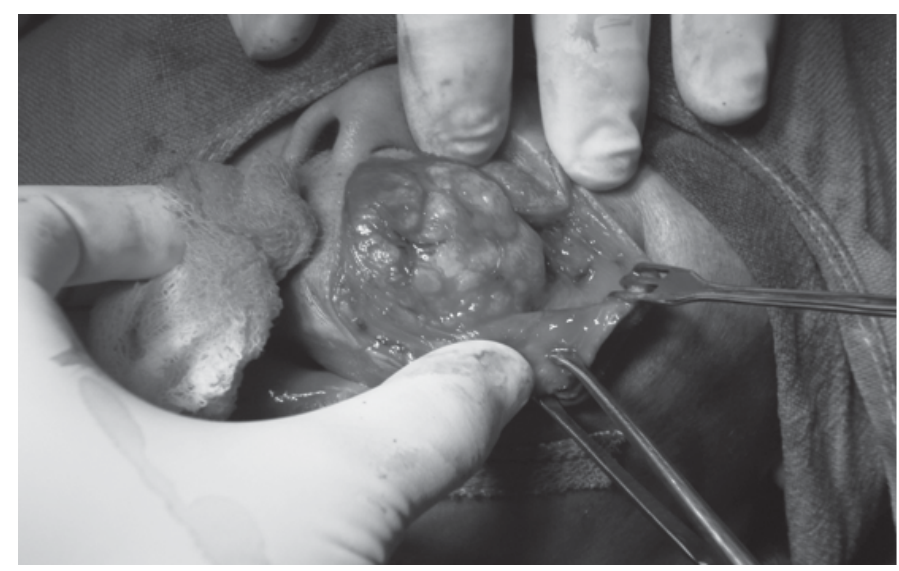

Fig-3

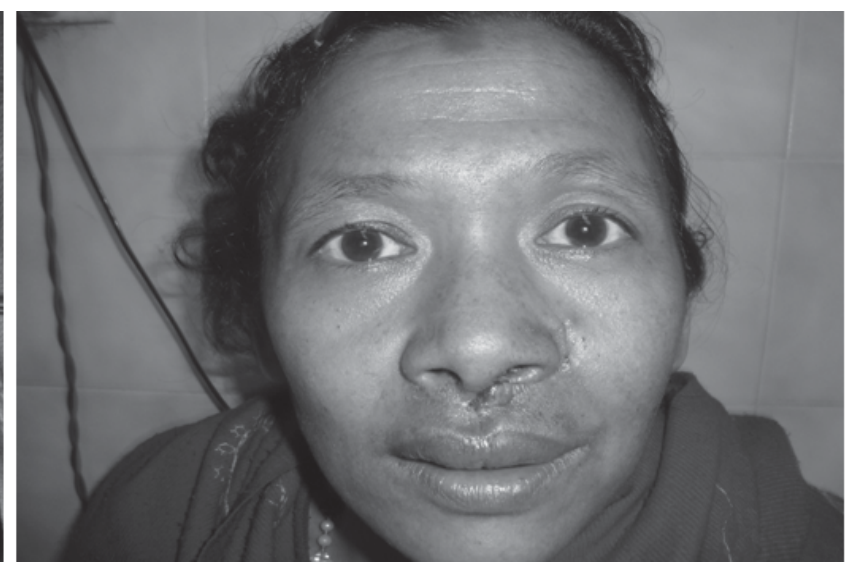

Fig-4

Hstopathological analysis of the surgical specimen revealed pleomorphic adenoma and there was no evidence of malignancy. Fig- 4 is $7^{\text {th }}$ post-operative day photo of the same patient.

\section{Discussion}

Kroll and Hick ${ }^{5}$ reviewed 4042 cases of pleomorphic adenomas of the salivary glands. Of these, 445 originated in the minor salivary glands, only $16.9 \%$ were located in the upper lip and $2.9 \%$ in lower lip. Pleomorphic adenoma in the upper lip exceeds that of the lower lip by the ratio of $6: 1$. The reason for this difference has been thought to be due to the differences in embryonic development between the upper and lower lips.

Pleomorphic adenoma arising from minor salivary glands of the lips tends to occur at an earlier age than it does at other sites. Bernier ${ }^{6}$ found that the peak incidence of pleomorphic adenoma of the lips was in 


\section{A. Shrestha et al. Pleomorphic adenoma of the upper lip: A case report}

the third and fourth decades, with an average age of 33.2 years. There is a propensity for benign tumor to occur in the upper lip, whereas malignant lesions to predominate in the lower lip. ${ }^{3,7}$ Owens and Calcaterra ${ }^{8}$ found $90 \%$ of the upper lip tumors to be benign in reports in the literature. Eveson and Cawson ${ }^{3}$ documented $75 \%$ of upper lip tumors as benign. In the study by Neville et $\mathrm{al}^{9}, 92 \%$ of the upper lip tumors were monomorphic adenoma (canalicular adenoma and basal cell adenoma) and pleomorphic adenoma, whereas sporadic cases of adenoid cystic carcinoma, acinic carcinoma, and adenocarcinoma constitute the remainder. Malignant tumors tend to predominate in the lower lip. Owens and Calcaterra ${ }^{8}$ found that 7 of the 13 malignant tumors in the lower lip were mucoepidermoid carcinoma. This finding was also consistent with the report from Neville et $\mathrm{al}^{9}$, which confirmed mucoepidermoid carcinoma to be compose more than $80 \%$ of lower lip tumors.

Minor salivary gland tumor presents as soft or firm masses, with most having a nodular, exophytic component. Ulceration of the nodular mass may occur, but the presence of ulcer provides no clue to the invasiveness of the tumor. Those that are soft on palpation usually have large cystic cavities and an abundance of mucin. The more solid tumors, especially pleomorphic adenoma with bone and cartilage formation, are firm on palpation. Differentiation between benign and malignant tumors is not possible without histopathology. However, suspicion of malignancy necessitates a biopsy before surgical treatment. When a lip mass is freely movable and submucosal, an excision of the mass with surrounding tissue may be adequate. On the other hand, a multilobulated mass fixed to the underlying tissue is more likely to be malignant. A wide local excision with a 1.5 $\mathrm{cm}$ margin and resection of 1 anatomic barrier beyond the tumor are necessary for surgical clearance. This will sacrifice the overlying and adjacent mucosa, the orbicularis oris muscle, and even the involved external skin of the lip. Reconstruction is effected by local tissue advancement or Abbe flaps. ${ }^{10}$

\section{References:}

1. Forty MJ, Wake MJC. Pleomorphic salivary adenoma in an adolescent. Br Dent J 2000; 188: 545-6

2. Chaudhry AP, Vickers RA, Gorlin RJ. Intraoral minor salivary gland tumors: An analysis of 1414 cases. Oral Surg 1961;14: 1194

3. Eveson JW, Cawson RA. Tumors of the minor (oropharyngeal) salivary glands: A demographic study of 336 cases. J Oral Pathol 1985; 14: 500

4. Farina A, Pelucchi S, Grandi E, Carinci F. Histological subtypes of Pleomorphic adenoma and age frequency distribution. Br J Oral Maxillofac Surg 1999;37: 154-5

5. Krolls SO, Hicks JL. Mixed tumors of the lower lip. Oral Surg 1973;35: 212

6. Bernier JL. Mixed tumors of lips. J Oral Surg 1946; 4: 193

7. Waldron CA, el-Mofty SK, Gnepp DR. Tumors of the intraoral minor salivary glands: A demographic and histologic study of 426 cases. Oral Surg Oral Med Pathol 1988;66: 323

8. Owens OT, Calcaterra TC. Salivary gland tumors of the lip. Arch Otolaryngol 1982;108: 45

9. Neville BW, Damm DD, Weir JC, et al. Labial salivary gland tumors. Cancer 1988;61:2113

10. Ord RA. Management of Intraoral salivary gland tumors. Oral Maxillofac Surg Clin North Am 1994;6:499 